\title{
Patient Travel Concerns After Treatment with ${ }^{177}$ Lu-DOTATATE
}

\author{
Ayşe Tuba Kendi ${ }^{1}$, Josh A. Mailman², Boris G. Naraev ${ }^{3}$, David J. Mercer ${ }^{4}$, James K. Underwood ${ }^{5}$, \\ and Thorvardur R. Halfdanarson 6

\begin{abstract}
${ }^{I}$ Division of Nuclear Medicine, Department of Radiology, Mayo Clinic, Rochester, Minnesota; ${ }^{2}$ NorCal CarciNET Community, Oakland, California; ${ }^{3}$ Banner M.D. Anderson Cancer Center, Gilbert, Arizona; ${ }^{4}$ Los Alamos National Laboratory, Los Alamos, New Mexico; ${ }^{5}$ Mayo Clinic Radiation Safety, Rochester, Minnesota; and ${ }^{6}$ Mayo Clinic Cancer Center, Rochester, Minnesota
\end{abstract}

\section{$\mathbf{S}$} ce its approval by the U.S. Food and Drug Administration in late January $2018,{ }^{177} \mathrm{Lu}$-labeled DOTATATE (Lutathera; Advanced Accelerator Applications, a Novartis company) has been used for the treatment of advanced somatostatin receptor-positive gastroenteropancreatic neuroendocrine tumors by over 150 hospitals and medical centers throughout the United States (1). In our experience, it is not uncommon for patients recently treated with ${ }^{177} \mathrm{Lu}$-DOTATATE to be stopped by U.S. Customs and Border Protection officers while traveling, especially when crossing the U.S. border at ports of entry, because of the detection of residual radiation activity. Detention at the border, even if temporary, can present significant challenges if the patients and their traveling companions are not properly prepared.

Because this is targeted systemic radiation therapy, federal safety regulations should be applied during and after ${ }^{177} \mathrm{Lu}$-DOTATATE administration. Before administration of systemic radionuclide therapy, a nuclear medicine physician or a nuclear radiologist who has authorized user status with competency in the administration of parenteral radioactive therapies needs to counsel the patient regarding details of the therapy, potential adverse effects, and radiation safety instructions that the patient needs to apply during therapy and after leaving the treating medical facility $(1,2)$.

Radiation emission after ${ }^{177} \mathrm{Lu}$-DOTATATE therapy is low, allowing the treatment to be done in the outpatient setting (1-3). Except for the first few days after therapy, there are no specific restrictions for contact with other persons $(1,2)$. Radiation activity persists at low levels for several weeks after therapy because of ongoing decay of the administered radionuclides (4). This radiation activity is not harmful to others but can be detected by sensitive radiation detectors at U.S. ports of entry, including international airports and border crossings by boat, car, or foot.

The therapy is most commonly given as 4 cycles with 2 mo between treatments. Traveling patients may need to go through U.S. ports of entry and high-security areas at some point during their therapy cycle and up to 3 mo after therapy completion. It is important to counsel patients in detail about the possibility of radiation detection when traveling in the first $6 \mathrm{wk}$ after each

Received Feb. 5, 2020; revision accepted Feb. 15, 2020.

For correspondence or reprints contact: Ayşe Tuba Kendi, Department of Radiology, Mayo Clinic, 200 First St. S.W., Rochester, MN 55905.

E-mail: kendi.ayse@mayo.edu

Published online Mar. 13, 2020.

COPYRIGHT (c) 2020 by the Society of Nuclear Medicine and Molecular Imaging. DOI: 10.2967/jnumed.120.243238 therapy cycle (2). Patients need to be provided with a card that they can carry at all times after each cycle of therapy, detailing the treatment they received. This card should also state that radioactivity can be detected for several weeks after therapy. After the last cycle, patients should carry the last card provided for an additional 3 mo. This card is called a travel card at most institutions, as patients encounter radiation detection mostly when they are traveling, especially when traveling abroad or going through U.S. ports of entry. These incidents are not limited only to U.S. borders and can happen at any place equipped with sensitive radiation detectors.

The travel card needs to have patient information, including the patient's personal identification, type of radiation received, dose of radiation administered, and date of administration. As security personnel at ports of entry may need to confirm this information, it is also important to provide information about the treating institution and contact information with $24 / 7$ access if further information is required.

Patients need to be advised that they may be delayed at various points of travel and to allow extra time when traveling, especially when transferring between international and domestic flights. If they are approached by a security officer, they should remain calm and be prepared to present the travel card. Patients should also be advised to carry a copy of their most recent clinic notes in a single envelope that is easily accessible when going through U.S. ports of entry and high-security areas.

A public online survey performed by one of our authors (Josh Mailman) showed that most of the patients are treated with respect at the U.S. ports of entry and high-security areas. However, screening procedures took around 1-2 $\mathrm{h}$, and in some cases even longer. Some of the patients reported that they had to go through screening with the radiation detectors multiple times and some of the portable detector systems were not able to correctly identify ${ }^{177} \mathrm{Lu}$, reporting other radionuclides instead. ${ }^{177} \mathrm{Lu}$ has a half-life of $6.6 \mathrm{~d}$, but a small amount of the metastable isomer ${ }^{177 \mathrm{~m}} \mathrm{Lu}$ will also be present, with a half-life of $160 \mathrm{~d}$. ${ }^{177 m} \mathrm{Lu}$ produces a gamma-ray signature at $413.66 \mathrm{keV}$ (among others), which is very similar to a $413.71-\mathrm{keV}$ signature of a plutonium isotope $\left({ }^{239} \mathrm{Pu}\right)$. Following the first customs detection of a ${ }^{177} \mathrm{Lu}$-DOTATATE patient in 2005, U.S. government researchers from National Laboratories of Los Alamos, Sandia and Lawrence Livermore tested the most popular hand-held commercial radiation detector/identifiers and found that most of them, including high-end systems, tended to misreport ${ }^{239} \mathrm{Pu}(5)$. Instrumentation engineers have made considerable improvements in identification algorithms since then, but 
occasional errors still occur. If there is a reading from radiation detectors suggesting plutonium, further review of the data by a trained human analyst is needed for a final decision/clearance. This most likely contributes to the additional waiting time that patients mentioned in the survey.

Given the ongoing increase in radionuclide therapies with different radiotracers, frequent communication between the Food and Drug Administration, the Nuclear Regulatory Commission, and Homeland Security/Border Patrol will be helpful to keep the staff up to date on the current use of medical isotopes and to help Homeland Security/Border Patrol make appropriate equipment choices that allow our patients to travel without long hours of waiting at the borders, while still providing high-level security at the borders.

Traveling while undergoing ${ }^{177} \mathrm{Lu}$-DOTATATE treatment should be discussed with the patient by the clinical care team and nuclear medicine or nuclear radiology team before treatment to avoid any unwanted surprises. Patients can arrange their schedules accordingly if they are well informed about this process ahead of time.

\section{DISCLOSURE}

No potential conflict of interest relevant to this article was reported.

\section{REFERENCES}

1. Kendi AT, Halfdanarson TR, Packard A, et al: Therapy with ${ }^{177} \mathrm{Lu}$-DOTATATE: clinical implementation and impact on care of patients with neuroendocrine tumors. AJR. 2019;213:309-317.

2. Hope TA, Abbott A, Colucci K, et al. NANETS/SNMMI procedure standard for somatostatin receptor-based peptide receptor radionuclide therapy with ${ }^{177} \mathrm{Lu}$ DOTATATE. J Nucl Med. 2019;60:937-943.

3. Calais PJ, Turner JH. Radiation safety of outpatient ${ }^{177} \mathrm{Lu}$-octreotate radiopeptide therapy of neuroendocrine tumors. Ann Nucl Med. 2014;28:531-539.

4. Gleisner KS, Brolin G, Sundlov A, et al. Long-term retention of ${ }^{177} \mathrm{Lu} /{ }^{177 m} \mathrm{Lu}-$ DOTATATE in patients investigated by $\gamma$-spectrometry and $\gamma$-camera imaging. J Nucl Med. 2015;56:976-984.

5. Mercer DJ, Blackadar JM, Dietrich DD, Smith DK, Lasche GP, Waymire DR. U.S. government capabilities to support analysis of gamma ray data submitted by field elements. Paper presented at: INMM 46th Annual Meeting; July 10-14, 2005; Phoenix, AZ. 